\title{
PROFISSÃO, DOCENTE DE ODONTOLOGIA: O DESAFIO DA PÓS-GRADUAÇÃO NA FORMAÇÃO DE PROFESSORES
}

\author{
TEACHING OF DENTISTRY:THE POST-GRADUATE CHALLENGE IN EDUCATOR TRAINING
}

\author{
Mariângela Monteiro de Melo Baltazar ${ }^{1}$ \\ Samuel Jorge Moysés ${ }^{2}$ \\ Carmen Célia Barradas Correia Bastos ${ }^{3}$
}

Resumo O presente artigo é resultante de intensa busca nos referenciais teóricos sobre a temática universidade e formação docente e se propõe a analisar a formação do docente de odontologia, à luz dos antecedentes históricos da instituição universidade no mundo e no Brasil. Faz a identificação dos conflitos que colocam a universidade contemporânea em crise, identifica o início da atividade docente na história da humanidade e sua trajetória até os dias atuais, bem como as condições de profissionalização do docente do ensino superior, apontando para o modo como se deu a formação e a atividade dos primeiros docentes de odontologia no Brasil e as possíveis implicações para os dias atuais. A partir destes relatos e por meio de busca nos cadernos de indicadores da Coordenação de Aperfeiçoamento de Pessoal de Nível Superior (Capes) do triênio 2004-2007 e de referenciais teóricos recentes sobre o tema da formação do docente de odontologia, em particular, buscou-se analisar as pós-graduações stricto sensu em Odontologia no Brasil e, assim, contribuir para o debate acerca dos problemas na formação dos profissionais da saúde, especificamente nessa área. O estudo não teve por objeto de análise o PróSaúde, podendo, este aspecto, ser uma limitação.

Palavras-chave formação docente; competências pedagógicas; odontologia; pós-graduação stricto sensu.
Abstract This article is the outcome of an intense search in theoretical references on the university and professor training subject and aims to analyze the training given to dentistry professors in the light of the historical background of the university institution in the world and in Brazil. It identifies the conflicts that put the contemporary university in crisis, identifies the start of the teaching activity in the history of mankind and its history to the present day, and the conditions under which university professors are trained, pointing to how the first dentistry faculty were trained in Brazil and to their activities and the possible implications of this for the present day. Based on these reports, and by surveying the indicator books of the Coordination for the Improvement of Higher Level Personnel (Capes) from 2004 to 2007 and recent theoretical references on the professor of dentistry training issue, in particular, we sought to examine the stricto sensu post-graduate work in dentistry in Brazil and, thus, contribute to the debate about the problems in the training of health professionals, specifically in this area. The study was not aimed to analyze the "Pró-Saúde" (Pro-Health), and this aspect may be a limitation.

Keywords teacher training, teaching skills, dentistry, stricto sensu post-graduate studies. 


\section{Introdução}

O paradigma da educação e da formação em saúde, hegemônico no mundo ocidental, filia-se à proposta geral contida no Relatório Flexner (1910), cuja característica principal é a predominante atenção ao estudo e à pesquisa nas ciências básicas e especializadas com aprimoramento do conhecimento de forma avançada, contudo, fragmentada e dissociada do contexto social. Estas características podem possibilitar um aprofundamento e ampliação do conhecimento nas diferentes especialidades, mas limitando a visão e distanciando a pesquisa e a ciência, propriamente dita, do ser humano em seu contexto amplo (Flexner, 1910).

A constatação deste perfil formador e a verificação dos indicadores de saúde bucal da população brasileira, apresentados no levantamento epidemiológico em base nacional (Brasil, 2005), indicam um descompasso da atuação da força de trabalho em odontologia em relação às necessidades epidemiológicas da população (Narvai, 1994). O modelo de formação de quem ensina e forma esta força de trabalho, entre outros aspectos, pode contribuir para que este descompasso permaneça.

No compasso das reformas ocorridas no mundo, com o ideário do 'bemestar social', um arcabouço legal foi constituído paulatinamente no Brasil: a Constituição de 1988, por meio da Lei Orgânica da Saúde, personificada nas leis n. ${ }^{\circ} 8.080 / 90$ e n. ${ }^{\circ} 8.142 / 90$ (Brasil, 1990a, b); a Lei de Diretrizes e Bases da Educação Nacional (lei n. ${ }^{\circ}$ 9.394/1996) (Brasil, 1996); e as Diretrizes Curriculares Nacionais (lei n. ${ }^{\circ}$ 9.131/95) (Brasil, 1995) são instrumentos oficiais que têm fundamentado as discussões a respeito das políticas públicas de educação em nível superior em todas as áreas, especialmente no setor saúde. Este setor tem experimentado algumas mudanças no cenário da graduação sem, contudo, concretizar um novo modelo de formação no âmbito da graduação e, primariamente, na pós-graduação (Almeida, 1999).

O ensino superior em saúde, de modo geral, e o ensino odontológico, em particular, têm passado por processos de mudanças e discussões intensas no que se refere às funções e finalidades gerais de seus programas, que deveriam “desenvolver, no estudante, o potencial intelectual, a capacidade de análise, julgamento e avaliação crítica, a habilidade para resolver problemas, o raciocínio crítico, a abordagem criativa e inquiridora" (Mamede, 2001, pág. 43).

Quando o ensino de graduação se fundamenta na especialização, tornase inevitável a separação da parte em relação ao todo, o que distancia o todo de seu contexto, dificultando a necessária habilidade criativa, inquiridora e crítica da força de trabalho para a resolução dos problemas que acometem o homem em sociedade (Morin, 1999).

O reducionismo e o determinismo eliminam a possibilidade de reflexão e resolução de alguns problemas do ser humano pelo ser humano. Tal situação 
é consequente de um sistema de ensino fragmentado, em que se perde conhecimento, não obstante o excesso de informação. A educação torna-se técnica, acrítica, sem capacidade de aprofundamento para questionar e refletir acerca da condição humana, que perpassa por conhecimentos científicos e humanísticos necessários para a compreensão do homem, que é um ser biológico, social e cultural (Morin, 1999).

Com esta perspectiva crítica pretende-se fazer emergir neste texto alguns fatos históricos da ciência e da origem da instituição universitária, em diferentes períodos, de modo a compreender a influência destes na formação do docente de ensino superior em Odontologia nos dias atuais.

\section{A universidade no mundo: aspectos históricos e conceituais da instituição universitária}

A instituição que hoje leva o nome de universidade teve origem na Idade Média e sua perenidade, sobretudo no mundo ocidental, revela o caráter refratário a mudanças. A sua estruturação está associada à rigidez funcional e organizacional e está sendo duplamente desafiada nos dias atuais. Há exigências cada vez maiores por parte da sociedade, ao mesmo tempo em que ocorrem políticas restritivas ao financiamento desta instituição por parte dos Estados nacionais (Santos, 2008).

Ao remeter o pensamento para a dimensão histórica dessa instituição, identificam-se quatro períodos: o primeiro, do século XII até o Renascimento; o segundo começa no século XV; o terceiro período se dá na transição do século XVII e XVIII; e o quarto período, instituindo a universidade moderna, começa no século XIX até os dias atuais.

No primeiro período, no século XII, constitui-se o modelo da universidade tradicional, a partir das experiências precursoras de Bologna, Oxford e Paris. Em Bologna, ela surge pela organização da corporação de estudantes livres, em Oxford, pela iniciativa do Estado Autônomo e, na Universidade de Paris, pela manutenção da ordem religiosa. O que se pode resgatar do modelo medieval é uma concepção de instituição universitária com três elementos básicos: centralmente voltada para uma formação teológico-jurídica que responde às necessidades de uma sociedade dominada por uma forte visão religiosa; uma organização corporativa em seu significado originário medieval; e preservação de sua autonomia em face do poder político e da Igreja institucionalizada local (Trindade, 1999). Sobre a Universidade Medieval, AlmeidaFilho (2007) acrescenta ainda como característica a rigidez curricular fortemente dependente da força que a religião exercia sobre o Estado.

$\mathrm{O}$ segundo período, que se inicia a partir do século XV, se dá na época em que a universidade renascentista sofre o impacto das transformações 
comerciais do capitalismo e do humanismo literário e artístico que floresce nas repúblicas urbanas da Itália e se estende para os principais países da Europa central e do norte (Trindade, 1999). Este período é marcado, também, pela incorporação das escolas médicas à instituição universitária da época como faculdade de medicina (Santos, 2008) e então passa a compor, juntamente com os cursos de Direito e Teologia, as 'faculdades superiores', restando a denominação 'faculdades inferiores' para as que ofertavam os cursos de Filosofia. A formação tecnológica ficava, nesta época, às margens das universidades, sendo objeto das escolas militares para o desenvolvimento das engenharias ou, de cunho estatal, para o desenvolvimento náutico, como a Escola de Sagres.

A partir do século XVII, com o avanço do Iluminismo do século XVIII e, também, pelo início da Revolução Industrial inglesa, a universidade passou a inserir a ciência em seu interior numa transição para os modelos que se desenvolveriam no século XIX. Este período ainda é marcado pela origem das primeiras cátedras científicas e o surgimento dos primeiros observatórios, jardins botânicos, museus e laboratórios científicos. Têm-se, aí, a institucionalização da ciência (Habermas, 1993).

Até o século XVII, o papel do cientista na sociedade não era significativo, mas desde então foi desencadeada uma mudança profunda, conquistada por intensos conflitos no sistema de valores e normas universitárias, reconhecendo-se a legitimidade de uma atividade relacionada com as ciências em geral. A inserção das ciências nas universidades alterou irreversivelmente a estrutura da instituição, limitada anteriormente às ciências ensinadas nas faculdades de medicina e artes sob a denominação 'filosofia natural' (Habermas, 1993; Trindade, 1999).

Com o Renascentismo, a universidade sentiu necessidade de transformar-se enquanto instituição social, abandonando seu padrão tradicional teológico-jurídico-filosófico e se abrindo ao humanismo e às ciências, interpondo, assim, os diferentes padrões da universidade moderna do século XIX (Trindade, 1999; Santos, 2008).

No final do século XVIII, Immanuel Kant propôs uma reforma da instituição universitária, para que esta deixasse de obedecer aos princípios religiosos e políticos e passasse a constituir um espaço livre em que não houvesse magister, soberano ou pontífice para atestar a verdade conforme suas convicções e interesses (Almeida-Filho, 2007), inserindo-se, neste momento, o conceito de autonomia universitária.

No início do século XIX, precisamente em 1810, foi divulgado o Relatório Humboldt, que estabelecia o primado da pesquisa e a repartição dos campos de conhecimentos nas chamadas cátedras, conceito que estrutura a organização curricular até os dias atuais e dá início ao quarto período. Foi instituída a universidade moderna, introduzindo uma nova relação com o 
Estado. Destaca-se, neste período, a implantação de uma rede de universidades conforme a Reforma Humboldtiana, principalmente na Alemanha e Inglaterra (Trindade, 1999). O modelo adotava os princípios e as diretrizes do Relatório Humboldt e possibilitou a criação de um mandato institucional e político sobre a produção da ciência, e, dessa forma, a universidade trouxe para dentro de si a prerrogativa da produção científica (Habermas, 1993; Almeida-Filho, 2007).

Enquanto na Europa se consolidava uma rede de universidades por toda sua extensão, também na América esta instituição aportou. No século XVI, no Caribe, foi implantada a primeira universidade inspirada no modelo tradicional espanhol, e as colônias norte-americanas da costa Atlântica, após, copiaram o modelo dos colégios ingleses, adotando-os a partir de 1636, em Cambridge (Harvard), Filadélfia, Yale, Princeton e Columbia (Trindade, 1999).

É importante ressaltar que há um padrão diferenciado no ensino superior da América Latina. Na América espanhola, a universidade se implantou após a conquista e, até fins do século XVII, existia uma rede de 12 instituições de norte a sul do continente. A primeira é de 1538, em Santo Domingo, na América Central; em 1613, é fundada pelos jesuítas a sexta universidade, situada em Córdoba, na Argentina. O modelo espanhol transplantado para a America Latina traz consigo a tradição da velha Universidade de Salamanca, mas, sobretudo, o da nova Universidade de Alcalá (Trindade, 1999).

No Brasil, a instituição 'universidade' se dá apenas no século XX, sem desprezar os relatos de existência de escolas e faculdades profissionais isoladas que datam desde 1808, quando da transferência da Corte Portuguesa para o Brasil, quando o príncipe regente cria o primeiro curso de Cirurgia, Anatomia e Obstetrícia (Cunha, 2007). A universidade, como é concebida hoje, apenas se organiza a partir da década de 1920. Para Teixeira (1989), o Brasil esteve fora do processo universitário quando o tema principal do debate, no século XIX, era 'a nova universidade', devotada à pesquisa e à ciência. Os temas do ensino superior e atividade docente no Brasil serão pormenorizados adiante.

No cenário norte-americano do início do século XX, ocorreu uma reforma universitária induzida pela sociedade civil, representada pelo grande capital. Nesta época deu-se início às fundações filantrópicas que assumiram como primeira grande missão social avaliar a estrutura do ensino universitário norte-americano, particularmente a do ensino médico, por meio da instituição de uma comissão. Tal comissão foi presidida por Abraham Flexner. Esta reforma teve implicações focadas principalmente no setor saúde, mas trouxe implícito um projeto de rearranjo da arquitetura universitária americana. No plano acadêmico, instituiu-se uma formação básica e flexível antes da graduação, e no plano organizacional, instituiu-se o sistema departamental em substituição ao regime das cátedras (Mendes e Badeia, 1985; Badeia, 1996; Pagliosa e Da Ros, 2008). 
A concepção de produção do conhecimento introduzido pelo modelo norte-americano, e que se instalou no mundo ocidental, trouxe consigo uma visão mecanicista de mundo, em que a neutralidade e a quantificação tornaram-se preponderantes e, ainda, o predomínio da razão instrumental distanciou a produção do conhecimento humano da possibilidade de se trabalhar as dimensões subjetivas e éticas do conhecimento (Mendes e Badeia, 1985; Badeia, 1996; Cunha, 2000; Pagliosa e Da Ros, 2008).

$\mathrm{O}$ incentivo à criação de institutos e centros de pesquisas autônomos dos departamentos universitários, característica marcante deste modelo, proporcionou grande autonomia aos pesquisadores individuais ou em grupos, sendo que o modelo norte-americano tornou-se excessivamente dependente das agências de financiamento de pesquisas e fortemente influenciado pelo mercado de trabalho (Orso, 2003).

Já a Europa, ao longo do século XX, conviveu com diversos modelos de formação em nível superior, autônomos e, em tese, incompatíveis entre si. Apenas com a consolidação da União Europeia, tornou-se imperativa a padronização dos sistemas de formação profissional dos países-membros, e a Declaração de Bologna, assinada por esses países, desencadeou o chamado 'Processo de Bologna'. Assim, em 1999, inicia-se a mais recente reforma universitária que estabelece compatibilidade plena entre os sistemas de ensino superior da União Europeia, tendo como prazo final para sua incorporação o ano de 2010 (Almeida-Filho, 2007; Cotta, 2007; Namen, 2007; Zarkowski, 2002; Sanz, 2008).

\section{Transitando no campo das tensões: definições, ideias e concepções de universidade na contemporaneidade}

Por definição, segundo Jasper (1965 apud Santos, 2008), a universidade, por concessão do Estado e da sociedade, configura-se como o lugar em que se pode cultivar a mais lúcida consciência de si própria numa determinada época. Desta definição surgiram os três grandes objetivos clássicos da universidade: a investigação, o ensino e a prestação de serviços (Habermas, 1993; Silva, 2006).

Em 1987, o relatório da Organização para a Cooperação e Desenvolvimento Econômico (OCDE) (Santos, 2008) sobre as universidades atribuía a estas dez funções principais: educação geral pós-secundária; investigação; fornecimento de mão de obra qualificada; educação e treinamento altamente especializados; fortalecimento da competitividade da economia; mecanismo de seleção para empregos de alto nível através da credencialização; mobilidade social para os filhos e filhas das famílias operárias; prestação de serviços à região e à comunidade local; paradigmas de aplicação de políticas nacionais e preparação para os papéis de liderança social. 
Esta multiplicidade de funções expõe a incompatibilidade entre algumas delas. Sabidamente, a função de ensino colide com a função de investigação, por ser esta uma função mobilizadora de uma quantidade de recursos humanos, financeiros e institucionais, na maioria das vezes, intransferíveis para as tarefas de utilização do conhecimento (Santos, 2008)

$\mathrm{Na}$ investigação, os interesses dos pesquisadores podem não coincidir com os do Estado e da sociedade. No que se refere ao ensino, os objetivos da educação geral e da preparação cultural colidem frontalmente com os da formação profissional ou da educação especializada.

Steiner (2006) expõe as contradições e mal-estar existentes na concepção de universidade pela sua própria criação, pois esta instituição nasceu "à sombra de poderes que ela estava destinada a questionar" (Steiner, 2006, p. 13). Entre outras coisas, entender que a universidade deve ser contemplativa e crítica; distanciar-se para se dar conta do todo, mas, ao mesmo tempo, aproximar-se da realidade imediata; formar as novas gerações sem perder o foco do passado; preservar tradições e romper paradigmas; aperfeiçoar a técnica e saber lidar com os limites da ética. Estas prerrogativas, próprias da universidade, colocam-na em constante crise.

Os problemas desencadeados pela crise da universidade ocorrem em três dimensões: 'a crise de hegemonia', quando uma dada condição social deixa de ser considerada necessária, única e exclusiva; 'a crise de legitimidade', quando uma dada condição social deixa de ser consensualmente aceita; e 'a crise institucional', quando uma dada condição social estável e autossustentada deixa de poder garantir os pressupostos que asseguram sua reprodução (Santos, 2008).

Para Santos (2008), estas modalidades de crise no interior das universidades se expressam pela incapacidade de desempenhar a contento as atribuições contraditórias, o que leva a sociedade e mesmo o Estado a buscarem alternativas para que sejam atingidos os objetivos delegados. Isto caracteriza a perda de hegemonia. Na expressão da crise de legitimidade ocorre a falência dos objetivos coletivos assumidos pela instituição, como, por exemplo, dar respostas eficientes aos problemas apresentados pela sociedade em relação às desigualdades sociais e à garantia de direitos. A crise institucional tem se dado na medida em que sua especificidade organizativa é colocada em dúvida e lhe são impostas modalidades organizativas vigentes em outras instituições tidas como mais eficientes.

Na compreensão destas tensões configura-se imprescindível resgatar as funções de investigação e ensino que necessariamente são desenvolvidas pela atividade docente no interior das universidades. Nesta perspectiva, é imperativo considerar o importante papel do docente universitário, sua identidade e as maneiras pelas quais tem ocorrido a formação ao longo do tempo. 
Diante deste desafio é prudente considerar que a universidade atualmente é compreendida como o lugar em que o ensino se constitui num processo de investigação e construção da ciência, mediante crítica ao conhecimento produzido, configurando seu importante papel na construção da sociedade (Pimenta, Anastasiou e Cavallet, 2003). Assim sendo, o ensino na universidade, por apresentar características específicas, também exige do docente competências específicas, que serão abordadas adiante.

\section{A universidade no Brasil}

O início dos cursos superiores no Brasil ocorreu tardiamente em relação a outros países da América Latina e América do Norte, no início do século XIX, data da vinda da família real para o país em função das guerras napoleônicas (Masetto, 1998; Chaui, 2003; Almeida-Filho, 2007).

As primeiras unidades de ensino superior no Brasil foram a Escola de Cirurgia da Bahia e do Rio de Janeiro, em 1808. No modelo universitário adotado, predominou o francês, porém não de modo integral, pois houve claramente uma mistura com o modelo norte-americano (Masetto, 1998).

As características que marcaram este modelo foram a supervalorização das ciências exatas e tecnológicas com a consequente desvalorização da filosofia, da teologia e das ciências humanas. Do modelo americano foi herdada a departamentalização dos cursos que eram voltados para a profissionalização. Assim, a formação universitária no Brasil, desde o início, tinha o caráter de formação profissional para exercer determinada profissão e cuja arquitetura dos cursos era fundamentada em departamentos (Masetto, 1998).

O modelo de educação superior que predominou no Brasil, desde a origem, se fundamentou fortemente no ensino vocacional ou profissionalizante, muito embora tenha havido importante resistência na Universidade de São Paulo (USP), em 1934 (Bastos, 2009).

Este movimento buscava a inserção de um modelo de educação universitária que priorizasse a formação humanista e foi desencadeado pelos idealizadores das primeiras universidades brasileiras, tendo, no entanto, curta duração, pois sempre foi alvo de críticas e sua força foi se exaurindo ao longo do tempo. Por fim, em 1938, passou a predominar no interior das universidades o caráter profissionalizante do ensino superior (Orso, 2003).

A formação profissional tinha o caráter de formar especialista em uma determinada área, na qual conhecimentos e experiências profissionais eram transmitidos, de um mestre que sabia, para o aluno, que não sabia e não conhecia, seguidos de avaliação de aptidão para que exercesse a profissão. Em caso de reprovação, o curso era refeito (Masetto, 1998). 
Cabe a reflexão sobre quem exercia e exerce a atividade de ensino universitário no Brasil. Para melhor entendimento, buscaram-se os cenários que marcaram a formação desta tão antiga atividade e que, modernamente, tem sido distinguida pela necessidade de consolidação de sua profissionalidade: a docência do ensino superior.

\section{A profissionalização do sujeito docente do ensino superior}

Entendendo universidade como espaço de educação, que se efetiva pela investigação e atividade docente nas funções de desenvolver, criar, criticar e transmitir a ciência, a técnica e a cultura, bem como preparar para o exercício de atividades profissionais pautadas na aplicação de conhecimentos, métodos científicos e artísticos e também respaldando técnica e cientificamente o desenvolvimento cultural, político, econômico das sociedades (Pimenta, Anastasiou e Cavallet, 2003), é premente compreender o processo histórico desta atividade para se estabelecer os conceitos atuais da profissão docente universitário.

A formação de professores para atuar no ensino elementar foi preconizada no século XVII, por Comênius, no entanto apenas no século XVIII, em 1774, na França, surgiu o primeiro curso com esta finalidade a que se deu o nome de Escola Normal (Bragato-Júnior, Caldeira, Fonseca et al., 2007). Este modelo espalhou-se pela Europa no decorrer do século XIX e objetivava formar professores para preencher os quadros das escolas recentemente criadas pelos sistemas públicos de ensino (Campos, 2006; Saviani, 2009). Além de França e Itália, países como Alemanha, Inglaterra e Estados Unidos também foram instalando, ao longo do século XIX, as Escolas Normais (Saviani, 2009).

A ideia do trabalho docente na perspectiva sociopolítica, integrante de uma estrutura de poder exposta na sociedade, é ainda prematura, pois durante grande parte do século XX esse trabalho era tido como uma missão a ser cumprida por alguém desinteressado das benesses materiais da sociedade e num contexto de sacerdócio. A atividade de magistério em sua origem estava ligada ao conceito de vocação, legitimado por dom presente nos envolvidos. Aqui O professor, por longo período, era tido como aquele que guardava os bons costumes e responsável pelas atividades de orientação das futuras gerações. Suas atribuições ultrapassavam a transmissão do conhecimento e eram identificadas numa dimensão moral e disciplinadora (Cunha, 2007).

A força da ciência moderna, marcada pelo positivismo, trouxe para o trabalho docente a responsabilidade em formar o aluno cognitivamente, e o que antes era marcado pelo dom e pelo sacerdócio passa a ser pelo poder da ciência. 
O trabalho docente fugia dos tradicionais parâmetros das demais classes trabalhadoras, pois o trabalho intelectual era diferenciado do manual, não permitindo nenhuma identificação (Cunha, 2007). Para esta autora, a profissão docente era caracterizada pela autonomia presente nas profissões liberais, o que possibilitava aos profissionais exercê-la quando estes não estivessem disponíveis nas comunidades. Seguindo a lógica positivista, que provavelmente influenciou a constituição das cátedras nas universidades, foi proporcionado ao exercício da docência a liberdade de expressão e, em contrapartida, era assumida a neutralidade da ciência e a impossibilidade de influenciar os alunos com a sua visão de mundo.

No Brasil, os formadores eram profissionais diplomados nas universidades europeias, mas, com a expansão dos cursos superiores, houve a necessidade de se ampliar o corpo docente. Os cursos superiores estavam em busca de profissionais renomados, com significativo desempenho de sua atividade profissional e reconhecido pela sociedade. A forma de ingresso na carreira docente se dava pelo convite feito diretamente ao profissional para que este formasse profissionais tão competentes como ele (Masetto, 1998).

$\mathrm{O}$ trabalho docente era distinguido e prestigiado socialmente, servindo a pequenos contingentes da classe média e alta, mesmo no espaço das escolas públicas.

A crescente oferta de vagas pelas instituições de ensino superior, decorrente da democratização do acesso à escolarização, fez com que a profissão sofresse um processo crescente de desprestígio com repercussão na remuneração e com fortes mecanismos de controle sobre o exercício profissional, principalmente no que se refere aos aspectos quantitativos de sua produção intelectual (Cunha, 2007).

Ancorados nos fatores destacados anteriormente, as tecnologias da informação, a disseminação dos meios de comunicação de massa, o mercado de trabalho com fortes instabilidades e a indecisão sobre as necessidades de futuro têm abalado o prestígio do conhecimento formalizado nas universidades e influenciado a formação do professor na medida em que este não é mais o detentor exclusivo do conhecimento.

Em meio a esta crise, as exigências para a docência universitária vão além das habilidades específicas em sua área de conhecimento, passando por domínios das tecnologias da informação e de domínios políticos/pedagógicos que possibilitem, por meio da ação educativa, construir a sua formação consciente de uma sociedade caracterizada pela globalização, complexidade e contradições (Cunha, 2007).

No Brasil, quando se fala em formação do docente, a maioria das referências é voltada para a formação do professor da educação infantil, do ensino fundamental e médio. Além disso, a Lei de Diretrizes e Bases da Educação Nacional (LDB), lei n. ${ }^{\circ}$ 9.394/1996 (Brasil, 1995), que regula a educação na- 
cional, assume, no artigo 66, um caráter pontual e superficial quanto à formação do docente do ensino superior:

Art. 66 - A preparação para o exercício do magistério superior far-se-á em nível de pós-graduação, prioritariamente em programas de mestrado e doutorado.

Parágrafo único - O notório saber, reconhecido por universidade com curso de doutorado em área afim, poderá suprir a exigência de título acadêmico (Brasil, 1995).

A legislação educacional mais abrangente no Brasil, a LDB, não entende a docência para o ensino superior como um processo de formação e sim como preparação para esta atividade, apontando para que esta se dê prioritariamente em cursos de pós-graduações stricto sensu (Pimenta, Anastasiou e Cavallet, 2003).

De modo geral, as pós-graduações stricto sensu têm ofertado esta formação em disciplinas de 45 a 60 horas, em que o saber pedagógico é tido como um corpo de conhecimentos técnicos instrumentais, capaz de apresentar receitas às situações de ensino (Pimenta, Anastasiou e Cavallet, 2003).

Particularmente nas pós-graduações em Odontologia, com conceito Capes 5 ou mais para avaliação do triênio de 2007, e conforme informações contidas no Cadernos de indicadores da Capes para o ano de 2008 (Brasil, 2010), esta formação tem ocorrido, na maioria dos programas, por meio de disciplinas que variam de 60 a 90 horas e com diferentes configurações e denominações, dentre elas: Metodologia do Ensino Superior; Didática e Ensino Superior; Pedagogia Aplicada; Bases Pedagógicas aplicadas ao Ensino da Odontologia.

Apesar de considerar a exiguidade do tempo, é conferida ao aprendiz da docência alguma possibilidade de crescimento pedagógico. No entanto, deve-se levar em conta que este tempo de formação não é suficiente para profissionalizar qualquer profissional, incluindo-se aí a profissionalização do docente universitário (Pimenta, Anastasiou e Cavallet, 2003).

Faz-se necessário ponderar que, além dos conteúdos abordados nestas disciplinas, o modo como ocorrem o ensino e sua construção é fator fundamental e desencadeador da apreensão bem-sucedida por parte do professor em seu aprendizado. É recomendado que o aprendiz-docente seja conduzido a uma recomposição de sua experiência, de modo a revisar e construir novas formas de ensinar (Pimenta, Anastasiou e Cavallet, 2003).

Dentre as possibilidades de preparação pedagógica para o docente do ensino superior, têm-se como desafio e possibilidades metodológicas a interação entre a experiência e a história, entre uma experiência e outra ou outras, o embate das práticas como as contribuições da teoria, com suas leis, princípios e categorias de análise, num movimento de descobrir, pela observação, a teoria em ação, o processo de investigação da prática, de forma 
intencional, problematizando-a em seus resultados e no próprio processo efetivado (Pimenta, Anastasiou e Cavallet, 2003).

Outro aspecto a ser destacado nesta questão é a existência dos 'estágios docentes', que assumem o caráter obrigatório, em alguns casos, apenas para os bolsistas Capes; entretanto, é sabido que as bolsas desta instituição são insuficientes para todos os pós-graduandos, quer sejam em nível de doutorado ou de mestrado. Além deste aspecto, é prudente considerar que, diante da obrigatoriedade, existe a possibilidade de se cursar apenas para cumprir o que é obrigatório, sem que ocorra um aprofundamento na questão do 'aprender a ensinar' e na compreensão do 'aprender a aprender'.

\section{A formação do docente de odontologia no Brasil}

\section{As pós-graduações stricto sensu em odontologia no Brasil}

As grandes guerras mundiais deram início a uma demanda crescente por conhecimento científico no âmbito mundial, e no Brasil este crescimento se deu pela implantação das indústrias de substituição de importações, fortemente apoiada pelo governo Vargas para a transformação deste setor.

A pós-graduação brasileira teve início na década de 1930, a partir da proposta da criação do Estatuto das universidades brasileiras, mas apenas na década de 1940 é que o termo 'pós-graduação' foi utilizado formalmente, no artigo 71 do referido estatuto (Moysés, 2008).

Junto com a busca de conhecimentos científicos transformadores, iniciou-se também a institucionalização das pós-graduações no Brasil, com a criação de órgãos cuja existência se mantém até os dias atuais e cujas responsabilidades eram de fomento à pesquisa e à qualificação de alto nível em todas as áreas do país: a Sociedade Brasileira para o Progresso da Ciência (SBPC), em 1948, o Conselho Nacional de Desenvolvimento Científico e Tecnológico (CNPq), em 1951, e a Campanha Nacional de Aperfeiçoamento de Pessoal de Nível Superior (atual Capes) (Moysés, 2008).

Nos dias atuais, embora não tenha sido objeto de análise do presente texto, faz-se necessário referendar a portaria interministerial n. ${ }^{\circ} 2.101 / 2005$, que institui o Programa Nacional de Reorientação da Formação em Saúde (Pró-Saúde) como importante estratégia para alavancar mudanças nos cursos de graduação na área da saúde com possibilidade de este programa ter também repercussão na formação do docente por meio das pós-graduações stricto sensu. 


\section{Um retrato quanti-qualitativo das pós-graduações stricto sensu em Odontologia no Brasil}

Em outubro de 2008, segundo informações do Caderno de indicadores da Coordenação de Aperfeiçoamento de Pessoal de Nivel Superior (Capes, 2008), a odontologia brasileira contava com 92 cursos de pós-graduação stricto sensu em funcionamento (Quadro 1). A região Sudeste concentrava 66,3\% dos programas, o que equivale a 61 cursos, e as regiões Norte e Centro-oeste concentram $2,2 \%$, equivalendo a dois cursos em cada uma das regiões. Dos programas brasileiros em funcionamento na avaliação do triênio 04/05/06, apenas um obteve conceito 7 e três programas com conceito 6 , sendo que todos estão localizados na região Sudeste. O maior percentual dos programas e cursos apresenta conceito $3(39 \%) ; 33 \%$ com conceito $4 ; 24 \%$ com conceito $5 ; 3 \%$ com conceito 6 ; e $1 \%$ com conceito 7 . De um total de 55 programas que oferecem mestrado e doutorado, 42 obtiveram conceito 4 e 5 , e nove programas obtiveram conceito 3. Esta última informação é de grande importância na medida em que, para que estes possam ser reofertados, sua avaliação do próximo triênio deve ser superior a este conceito, caso contrário o programa é extinto.

Quadro 1

Distribuição das pós-graduações em Odontologia no Brasil, segundo região e conceito Capes, 2009

\begin{tabular}{|c|c|c|c|c|c|c|c|c|c|c|c|c|}
\hline Região & $3 \mathrm{M} / \mathrm{D}$ & $3 M$ & $3 P$ & $4 \mathrm{M} / \mathrm{D}$ & $4 M$ & $4 \mathrm{D}$ & $4 \mathrm{P}$ & $5 \mathrm{M} / \mathrm{D}$ & $5 \mathrm{P}$ & $6 \mathrm{M} / \mathrm{D}$ & $7 \mathrm{M} / \mathrm{D}$ & Total \\
\hline $\mathrm{CO}$ & 1 & 0 & 0 & 0 & 0 & 0 & 0 & 0 & 0 & 0 & 0 & $(1,1 \%)$ \\
\hline $\mathrm{N}$ & 1 & 0 & 0 & 0 & 0 & 0 & 0 & 0 & 0 & 0 & 0 & $(1,1 \%)$ \\
\hline $\mathrm{NE}$ & 0 & 7 & 1 & 3 & 2 & 1 & 0 & 0 & 0 & 0 & 0 & $(5,2 \%)$ \\
\hline SUL & 3 & 0 & 3 & 5 & 1 & 0 & 1 & 2 & 0 & 0 & 0 & $(16,3 \%)$ \\
\hline SE & 4 & 8 & 8 & 14 & 0 & 0 & 3 & 18 & 2 & 3 & 1 & $(66,3 \%)$ \\
\hline Total & 9 & 15 & 12 & 22 & 3 & 1 & 4 & 20 & 2 & 3 & 1 & 92 \\
\hline$\%$ & $9,8 \%$ & $16,3 \%$ & $13 \%$ & $24 \%$ & $3,3 \%$ & $1 \%$ & $4,2 \%$ & $22 \%$ & $2,1 \%$ & $3,3 \%$ & $1 \%$ & $100 \%$ \\
\hline Por conceito & & $39 \%$ & & & $33 \%$ & & & \multicolumn{2}{|c|}{$24 \%$} & $3 \%$ & $1,09 \%$ & \\
\hline
\end{tabular}

Fonte: Cadernos de indicadores da Capes - Triênio 2004-2007.

Notas: M - apenas mestrado; D - apenas Doutorado; M/D - Mestrado/Doutorado; P - mestrado profissionalizante. 
As pós-graduações stricto sensu em Odontologia no Brasil são, na sua maioria, em Odontologia ou em Clínica Odontológica. Nestes programas, ocorrem divisões nas áreas de concentração, e a formação de mestres e doutores se dá de modo fragmentado e dissociado do conhecimento necessário para dar respostas às mudanças iniciadas na graduação por meio das Diretrizes Curriculares Nacionais (DCN) (Pordeus, 2006).

A formação do docente na área da saúde, em particular em Odontologia, é marcada pela ausência ou insuficiência da formação didático-pedagógica. O professor de Odontologia, como qualquer outro professor, requer conhecimentos de como aprender a ensinar (Péret e Lima, 2006). No entanto, os programas de pós-graduação stricto sensu são marcados pelo reforço tecnicista ensinado nas graduações e pós-graduações lato sensu, e o 'aprender a ensinar' torna-se uma pequena partícula num universo de técnicas e novas tecnologias que dominam este cenário.

O perfil dos docentes que ocupam lugares nos cursos de graduação em Odontologia pelo Brasil tem se caracterizado pela excelência técnico-científica nas diversas especialidades da área. No entanto, este perfil necessita ser repensado, pois não tem sido suficiente para formar novos cirurgiões-dentistas que respondam às exigências das DCN, que por sua vez respondem às demandas da sociedade, levando-se em conta as diferentes dimensões do saber (Péret e Lima, 2006).

Muito embora os conhecimentos técnicos e os avanços tecnológicos tenham sido e sejam fundamentais para a eficiente intervenção nos problemas de saúde bucal da população, eles não são suficientes quando aspectos culturais, sociais, econômicos e políticos interferem nas condições de vida das populações, o que resulta em baixo impacto das ações de saúde bucal.

Os componentes essenciais para a construção de um novo perfil de docência em Odontologia necessariamente devem estar vinculados a processos metodológicos e saberes pedagógicos, filosóficos, políticos, humanísticos e também, mas não apenas, saberes técnicos e especializados de cada área.

$\mathrm{Na}$ área da saúde, a docência imprime duas condições ao professor. A primeira diz respeito a todo conhecimento técnico-científico acumulado, com saberes marcados pela vivência e práticas cotidianas e concretas que utiliza na educação de seus alunos e os coloca na condição de 'nativos'. No contraponto desta observação está a segunda condição, que se refere aos conhecimentos da docência relativos aos processos educacionais, psicológicos e filosóficos, aos quais, nesta condição, esses mesmos professores assumem a condição de 'estrangeiros'. O domínio teórico sobre o saber ensinar não é algo que constitui sua formação, e apenas a experiência como professor e o seu saber 'no campo da saúde' não bastam para formá-lo docente (Batista e Batista, 2004). 


\section{Finalizando o texto, mas não o debate...}

Para Morin (1999), nos primórdios do pensamento científico, foi fundamentalmente necessária a fragmentação do todo para se descobrir as partes. No entanto, as partes desagregadas e isoladas não respondem às exigências do todo. Para este autor, a religação das partes nos faria compreender novamente a totalidade do ser humano, independentemente de se trabalhar a multi, a trans, a poli ou interdisciplinaridade.

Os conhecimentos do homem devem respeitar e ser oportunizados pelas dimensões educacionais que, de acordo com Delors (2003), precisam estar presentes desde a formação básica, sendo elas: ético-cultural; científicotecnológica; econômico-social.

A formação em nível de graduação e em pós-graduação em Odontologia tem focado fortemente as dimensões técnico-científicas em detrimento das demais. Outro aspecto a ser considerado é que a necessária divisão dos saberes para se ter a 'cientificidade' requerida pelas universidades, até os dias atuais, desconsidera a compreensão do todo, e as ações são desagregadas das necessidades do ser humano, que é um ser social, político, cultural e biológico.

Para além das dimensões educacionais, nas políticas de formação dos profissionais da saúde existe a necessidade de mudanças nos modos de 'pensar-sentir-querer' (Ceccim, 2007). No entanto, este modo de pensamento coloca os profissionais docentes no foco da mudança em curso, quando, na verdade, esta deve ser contextual. As mudanças devem ocorrer em todos os cenários, seja no de formação em diferentes níveis, seja no de práticas de saúde/odontologia, levando-se em conta tanto as adaptações dos sistemas de educação quanto as dos serviços de saúde. O pensamento de reforma deve ser em longo prazo e não de reformas subsequentes ou em cascata, pois este acaba 'matando' a reforma propriamente dita (Delors, 2003), já que é desprovida da visão de futuro e de perspectivas dos cenários desejados.

Quando se tem políticas amplas, capazes de impulsionar mudanças como é o caso da LDB e do SUS, é necessário pensar na perspectiva de longo prazo, num cenário futuro o qual será requerido pela sociedade.

No sistema de saúde, as mudanças se iniciaram na atenção básica, de modo a garantir e/ou ampliar a resolutividade neste nível de atenção, para posteriormente ou concomitantemente ocorrerem os ajustes necessários nas altas e médias complexidades, na clara intenção de romper com o círculo vicioso de hospitalização e medicalização da sociedade.

No sistema educacional, tais mudanças deveriam ocorrer em sentido contrário, de modo a contemplar inicialmente a formação dos formadores, ou seja, as mudanças nas pós-graduações stricto sensu e, posteriormente, 
haver intervenções nas graduações, como consequência normal de uma mudança iniciada com a intenção de ruptura do círculo vicioso, que é o da formação tecnificada e fragmentada.

Iniciar as mudanças pela graduação, por meio das DCN, fez o corpo docente atual se colocar em situação desconfortável e desfavorável a mudanças, proporcionando fortes resistências e grandes chances de fracasso.

Sabidamente, para melhorar a qualidade da educação, em qualquer nível, nesse caso da Educação Odontológica, é preciso melhorar a formação docente, o recrutamento e composição do quadro docente, assim como as condições de trabalho e o sistema de avaliação (Delors, 2003).

No sistema de formação em nível de excelência, como nos programas de pós-graduação, é necessário ter em mente que sensíveis ajustes devem ser feitos em seu sistema de avaliação de modo que os vícios da educação fragmentada, cientificada e pouco humanizada não sejam perpetuados pelo sistema avaliador.

Faz-se necessário apontar como limitação do estudo o fato de não ter sido suficientemente explorado o Pró-Saúde como importante alavanca de mudanças na graduação, com possíveis repercussões nas pós-graduações stricto sensu e na formação de docentes de odontologia.

Assim, mudanças na graduação requerem mudanças nos programas de pós-graduação stricto sensu e, por consequência, no sistema de avaliação dos programas de formação docente. Desta maneira, as mudanças devem ser estruturadas e pensadas globalmente e em longo prazo, de modo que os cenários sejam antecipadamente vislumbrados, quer sejam na atuação dos formadores de formadores, quer seja na atuação dos docentes na graduação, quer seja na atuação profissional perante as necessidades da sociedade.

\section{Notas}

1 Professora assistente da Universidade Estadual do Oeste do Paraná (Unioeste), Cascavel, Paraná, Brasil. Doutoranda em Odontologia em Saúde Coletiva pela Pontifícia Universidade Católica do Paraná (PUC-PR). <mmmwgb@uol.com.br>

Correspondência: Rua Nossa Senhora do Rocio, 2.339, Jardim La Salle, CEP 86902-020, Toledo, Paraná, Brasil.

2 Professor titular da Pontifícia Universidade Católica do Paraná (PUC-PR), Curitiba, Paraná, Brasil. Doutorado em Epidemiology And Public Health pela University of London. $<$ s.moyses@pucpr.br>

3 Professora adjunta da Universidade Estadual do Oeste do Paraná (Unioeste), Cascavel, Paraná, Brasil. Doutora em Educação pela Universidade Estadual de Campinas (Unicamp). <carmencbcb@yahoo.com.br> 


\section{Referências}

ALMEIDA, Márcio José de. Educação médica e saúde: possibilidades de mudança. Londrina: UEL; Rio de Janeiro: Abem, 1999.

ALMEIDA-Filho, Naomar de. Universidade nova: textos críticos e esperançosos. Salvador: EDUFBA, 302 p., 2007.

BADEIA, Marcos. Tendências da pós-graduação em odontologia. Revista do CROMG, Belo Horizonte, v. 2, n. 1, p. 48-58, 1996.

BASTOS, Carmen C. B. C. Educação geral: possibilidades curriculares na universidade brasileira. In: SEMINÁRIO NACIONAL DE ESTUDOS E PESQUISA, 8., 2009, Campinas. Anais... Campinas: HISTEDBR, 2009.

BATISTA, Nildo. A.; BATISTA, Silvia H. Docência em saúde: temas e experiências. São Paulo: Editora Senac, 2004.

BRAGATO-JÚNIOR, Alberto D. C. et al. Os (des)caminhos da profissão docente no Brasil e o novo paradigma do professor pesquisador. Ensino em Re-Vista, Uberlândia, v. 14, n. 1, jul. 06/jul. 07, p. 73-90. 2007.

BRASIL. Lei Orgânica da Saúde. Lei n. ${ }^{\circ}$ 8.080, de 19 de setembro de 1990. Brasília, DF: Ministério da Saúde, 1990a.

Lei Orgânica da Saúde. Lei n. ${ }^{\circ}$ 8.142, de 28 de dezembro de 1990. Brasília, DF: Ministério da Saúde, 1990b.

Lei de Diretrizes e Bases da Educação Nacional. Lei n. ${ }^{\circ}$ 9.131, de 24 de novembro de 1995. Brasília, DF: Ministério da Educação, 1995.

Lei de Diretrizes e Bases da Educação Nacional. Lei n. ${ }^{\circ}$ 9.394, de 20 de dezembro de 1996. Brasília, DF: Ministério da Educação, 1996.

. Ministério da Educação. Coordenação de Aperfeiçoamento de Pessoal de Nível Superior. Cadernos de indicadores. 2008. Disponível em: <http://conteudoweb.capes.
gov.br/conteudoweb/CadernoAvaliacao Servlet? acao $=$ filtraArquivo $\&$ ano $=2008 \&$ codigo_ies=\&area=18> . Acesso em: 23 mar. 2010.

Ministério da Saúde. Secretaria de Atenção à Saúde. Departamento de Atenção Básica. Projeto SB Brasil 2003: condições de saúde bucal da população brasileira 20022003 - resultados principais. Brasília, DF: Ministério da Saúde, 2004, p. 68.: il. color. Série C. Projetos, Programas e Relatórios.

CAMPOS, Judas T. D. As políticas de formação dos professores paulistas antes, durante e depois da pedagogia tecnicista. Revista ecurriculum, São Paulo, v. 1, n. 1, dez.-jul. 2006.

CECCIM, Ricardo. B. Um sentido muito próximo ao que propõe a educação permanente em saúde: o devir da educação e a escuta pedagógica da saúde. Interface - Comunicação, Saúde, Educação, Botucatu, v. 11, p. 358-361, 2007.

CHAUI, Marilena. A universidade pública sob nova perspectiva. Revista Brasileira de Educação, Rio de Janeiro, n. 24, p. 5-15, set./dez. 2003.

COTTA, Rosângela M. M. et al. Pobreza, injustiça, e desigualdade social: repensando a formação de profissionais de saúde. Revista Brasileira de Educação Médica, Rio de Janeiro, v. 31, n. 3, p. 278-286, 2007.

CUNHA, Luiz. A. A universidade temporã: o ensino superior da colônia à era Vargas. São Paulo: Hucitec, 2007. 312 p.

CUNHA, Maria I. Ensino como mediação do professor universitário. In: (ed.). Professor do ensino superior: identidade, docência e formação. Brasília: Instituto $\mathrm{Na}$ cional de Estudos e Pesquisas Educacionais, 2000. p. 45-51.

. Reflexões e práticas em pedagogia universitária. Campinas: Papirus, 2007. 192 p.

DELORS, Jaques. Educação: um tesouro a descobrir. Relatório. Unesco. Comissão 
Internacional sobre educação para o século XXI. São Paulo: Cortez, 2003.

FLEXNER, Abraham. Medical Education in the United States and Canada - Bulletin Number Four (The Flexner Report). New York: The Carnegie Foundation for the Advancement of Teaching, p. 346, 1910.

HABERMAS, Josef. A idéia da universidade: processos de aprendizagem. Revista Brasileira de Estudos Pedagógicos, Brasília, v. 74, p. 176, 1993.

MAMEDE, Silvia; PENAFORTE, Júlio (org). Aprendizagem baseada em problemas: anatomia de uma nova abordagem educacional. Fortaleza: Hucitec, 2001.

MASETTO, Marcos. T. Docência na universidade. Campinas: Papirus, 1998. 112 p. Coleção Práxis.

MENDES, Eugênio V.; BADEIA, Marcos. Odontologia integral: bases teóricas e suas implicações no ensino e na pesquisa odontológicas. Belo Horizonte: Pontifícia Universidade Católica de Minas Gerais, Finep, 1985. 66 p.

MORIN, Edgar. A cabeça bem feita. São Paulo: Cortez, 1999. 128 p.

MOYSÉS, Samuel. Pós-graduação em saúde coletiva: propostas e desafios para a saúde bucal coletiva. In: MACAU, Mônica E. (ed.). Saúde bucal coletiva: implementando idéias, concebendo integralidade. Rio de Janeiro: Rubio, 2008. p. 87-98.

NAMEN, Fátima M.; GALAN JR., João; CABREIRA, Rodrigo D. Educação, saúde e sociedade. Revista Espaço para a Saúde, Londrina, v. 9, n. 1, p. 43-55, 2007.

NARVAI, Paulo C. Odontologia e saúde bucal coletiva. São Paulo: Hucitec, 1994. 113 p. Saúde em Debate.

ORSO, Paulino J. Liberalismo, neoliberalismo e educação: Roque Spencer Maciel de Barros, um ideólogo da burguesia brasileira. Tese
(Doutorado em Educação) - Faculdade de Educação, Universidade Estadual de Campinas, Campinas, 2003.

PAGLIOSA, Fernando. L.; DA ROS, Marco Aurélio. O relatório Flexner: para o bem e para o mal. Revista Brasileira de Educação Médica, Rio de Janeiro, v. 32, n. 4, p. $492-$ 499, 2008.

PÉRET, Adriana D. C. A.; LIMA, Maria D. L. As políticas públicas em educação e saúde e a formação do professor de odontologia numa dimensão crítica. In: CARVALHO, Antônio C. P.; KRIGER, Léo. (ed.). Educação odontológica. São Paulo: Artes Médicas, 2006, p.118-128.

PIMENTA, Selma G.; ANASTASIOU, Lea G. C.; CAVALLETT, Valdo J. Docência e ensino superior: construindo caminhos. In: BARBOSA, Raquel L.L. (org.). Formação de educadores?: desafios e perspectivas. São Paulo: Unesp, 2003. p. 267-289.

PORDEUS, Isabela; BUSATO, Adar L. S.; PEREIRA, José C. Aspectos conceituais norteadores da pós-graduação stricto sensu. In: CARVALHO, Antônio C. P.; KRIGER, Léo. (ed.). Educação odontológica. São Paulo: Artes Médicas, 2006. p. 185-202.

SANTOS, Boaventura V.D.S. Pela mão de Alice: o social e o político na pós-modernidade. São Paulo: Cortez, 2008. 348 p.

SANZ, Mariano et al. Profile of the dentist in the oral healthcare team in countries with developed economies. European Journal of Dental Education, v. 12, Suppl. 1, Feb., p. 101110, 2008.

SAVIANI, Demerval. Formação de professores: aspectos históricos e teóricos do problema no contexto brasileiro. Revista Brasileira de Educação, Rio de Janeiro, v. 14, p. 143-155, 2009.

SILVA, Franklin L. E. Universidade: a idéia e a história. Estudos Avançados, São Paulo, v. 20, p. 191-202, 2006. 
STEINER, João E.; MALNIC, Gerhard. Ensino superior conceito e dinâmica. São Paulo: Edusp, 2006.

TEIXEIRA, Anísio. Ensino superior no Brasil: análise e interpretação de sua evolução até 1969. Rio de Janeiro: Editora FGV, 1989. 186 p.

TRINDADE, Helgio. Universidade em perspectiva: sociedade, conhecimento e poder. Revista Brasileira de Educação, Rio de Janeiro, v. 1, n. 10, p. 5-15, 1999.
ZARKOWSKI, Pamela et al. The demography of oral diseases, future challenges and the implications for dental education. European Journal of Dental Education, v. 6, Suppl. 3, p. 162-6, 2002.

Recebido em 25/02/2010

Aprovado em 05/06/2010 
